\title{
The Corrosion of Mild Steel Checked by the Application of Octahydrodibenzo[a,d][8] Annulene-5,12-Dioxime and ZnSFiller in Corrosive Environments
}

\author{
Rajesh Kumar Singh*, Manjay Kumar Thakur and Shabana Latif \\ Department of Chemistry, India \\ *Corresponding author: Rajesh Kumar Singh, Department of Chemistry,Jagdam College, India,
}

Submission: 眥 May 21, 2018; Published: 笽 July 11, 2018

\begin{abstract}
Mild steel is economical metal so it is used in different appliances of industries, railways, bridges, construction works and marine water. Marine water produces corrosive environment for this metal. Marine water is saline in character so it corrodes mild steel. Poly-butadiene is coated on the surface of mild steel for corrosion protection. But this coating does not provide sufficient protection of base metal. Marine water is major absorber of $\mathrm{CO}_{2}$. It converts $\mathrm{CO}_{2}$ into $\mathrm{H}_{2} \mathrm{CO}_{3}$. Saline water and $\mathrm{H}_{2} \mathrm{CO}_{3}$ interacts with poly-butadiene-coated mild steel and they exhibit chemical and electrochemical reactions. This chemical reaction produces swelling and dissolving corrosion and produce disbonding between carbon and carbon of poly-butadiene. These corrosive agents show osmosis or diffusion process and inter inside the base metal and develop corrosion cell. Metal generates corrosion reaction which produces several forms of corrosion like galvanic, pitting, crevice, stress, intergranular, blistering and embrittlement. For the protection from such types of corrosions synthesized organic compounds octahydrodibenzo[a,d][8]annulene-5,12-dioxime was used and this compounds wasnanocoated on the surface of poly-butadiene-coated mild steel. During nanocoating used compound developed lot of porosities on the surface of poly-butadienecoated mild steel and they were blocked by the use of filler materials ZnS. The corrosion rate of material was calculated by gravimetric and potentiostat. Composite barrier formation was analyzed by activation energy, heat of adsorption, free energy, enthalpy and entropy.The results of surface coverage area and coating efficiency were indicated that compound octahydrodibenzo[a,d][8]annulene-5,12-dioxime and $\mathrm{ZnS}$ have good coating and filling properties.
\end{abstract}

Keywords: Marine environment;Nanocoating;Filler;Corrosion;Polybutadiene;Mild steel

\section{Introduction}

Corrosion is just like diabetes for materials. Corrosion control of materials is major problems. Develop nation's expense $5 \%$ their GNP for corrosion protection and repairing of materials. Corrosion occurs in metals, metalloids, ceramics, polymers, bio-metals, building materials and other type's metallic and nonmetallic equipments. There are several methods are applied for corrosion mitigation of materials [1] as per materials nature and environments. Generally must of metallic industries use metallic coatings but such types of coating do not provide good results in corrosive medium [2]. Now days some industries apply polymeric coating [3] for safe base metal in hostile atmosphere [4]. This coating does not provide protection [5] of base and its own. Disintegrations occur in base metal [6] and polymeric material [7]. Paint coating [8] is doing for building materials [9] and metal corrosion protection [10] in unfriendly atmosphere [11] but it is not protect itself and coating materials [12] for the attack of pollutants [13]. Organic [14] and inorganic inhibitors [15] are a very useful in acidic, basic and moist oxygen environment [16]. These inhibitors do not give good results after certain period. There are several types of inhibitors [17] like anodic, cathodic and mixed [18] of types use as nature environments of pollutants [19]. They do not provide satisfactory results in against pollutants [20]. Nanocoating techniques [21] are a very suitable method for corrosion protection materials in any type's corrosive ambient. Nanocoating substances forms composite thin film barrier, top layer coating, thermal barrier coating, conversion coating and nano scale structural change coatings on surface of base materials as per materials applications in different fields [22] to safe it's against heat, light, temperature, particulates, acidic, basic, salt, marine atmosphere, flues gases and biological environment [23]. Such types of coating produce lot of porosities and corrosive agents are entered inside by osmosis or diffusion process and produce interior and exterior corrosion. In this research work octahydrodibenzo [a,d] [8] annulene-5, 12-dioxime is used a nanocoating material and porosities are blocked by filler 
ZnS. These materials create composite barrier and it works repeller against corrosive pollutants.

\section{Experimental}

Poly-butadiene-coated mild steel kept in marine water and water sample was taken from Marina beach of Chennai (Tamil Nadu). Poly-butadine coated-mild steel (5X10X was in dipped into sea water and the corrosion rate was determined gravimetric methods at $283,293,303,313$ and $333{ }^{\circ} \mathrm{K}$ temperatures and time mentioned in given temperatures $2,5,8,11$ and 14 days. The samples were nanocoated with octahydrodibenzo [a,d] [8] annulene-5, 12-dioxime and immersed into sea water and corrosion rate recorded at above mentioned temperatures and days. Nanocoated samples were coated by ZnS filler and dipped into sea water to calculate the corrosion rate given temperatures and days. The corrosion potential, corrosion current, corrosion current densities were calculated by potentiostat technique. For these results pt electrode used as reference electrode, calomel as auxiliary electrode and polybutaine-coated mild steel sample electrode. Nanocoated compound octahydrodibenzo [a,d] [8] annulene-5, 12-dioxime was synthesized by given methods as:

\section{Scheme1: synthesis of 4-chloro-1, 2-dihydonaphthalene}

When 3, 4-dihydronaphthalen-1(2H)-one (25gm) is added into cold solution of benzene $(50 \mathrm{gm})$ containing $\mathrm{PCl}_{5}(30 \mathrm{gm})$, the reaction mixture was stirred for one hour. The reaction mixture was quenched with $\mathrm{NaHCO}_{3}$ and did workup with diethyl ether. The solvent evaporated with rotator vapor. The product was purified by silica gel column chromatography and produced 89\% 4-chloro-1, 2-dihydonaphthalene (Figure 1-3).

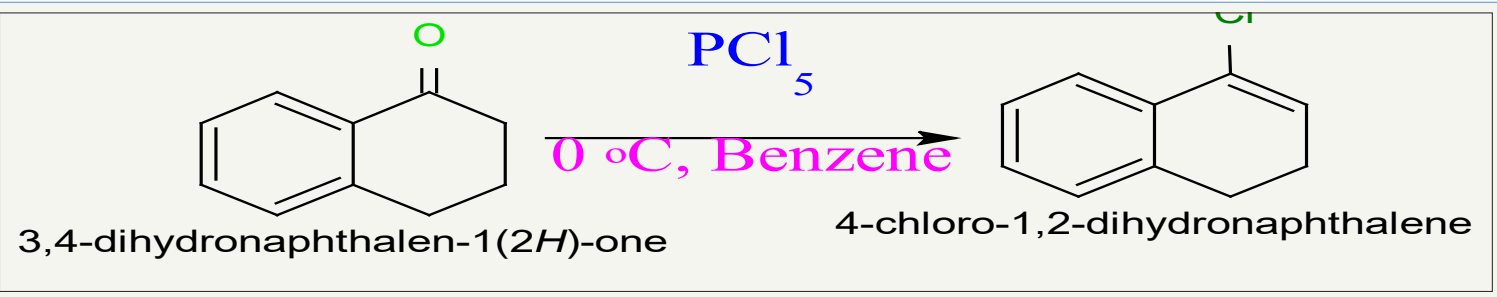

Figure 1: Physical properties of 4-chloro-1, 2-dihydronaphthalene.
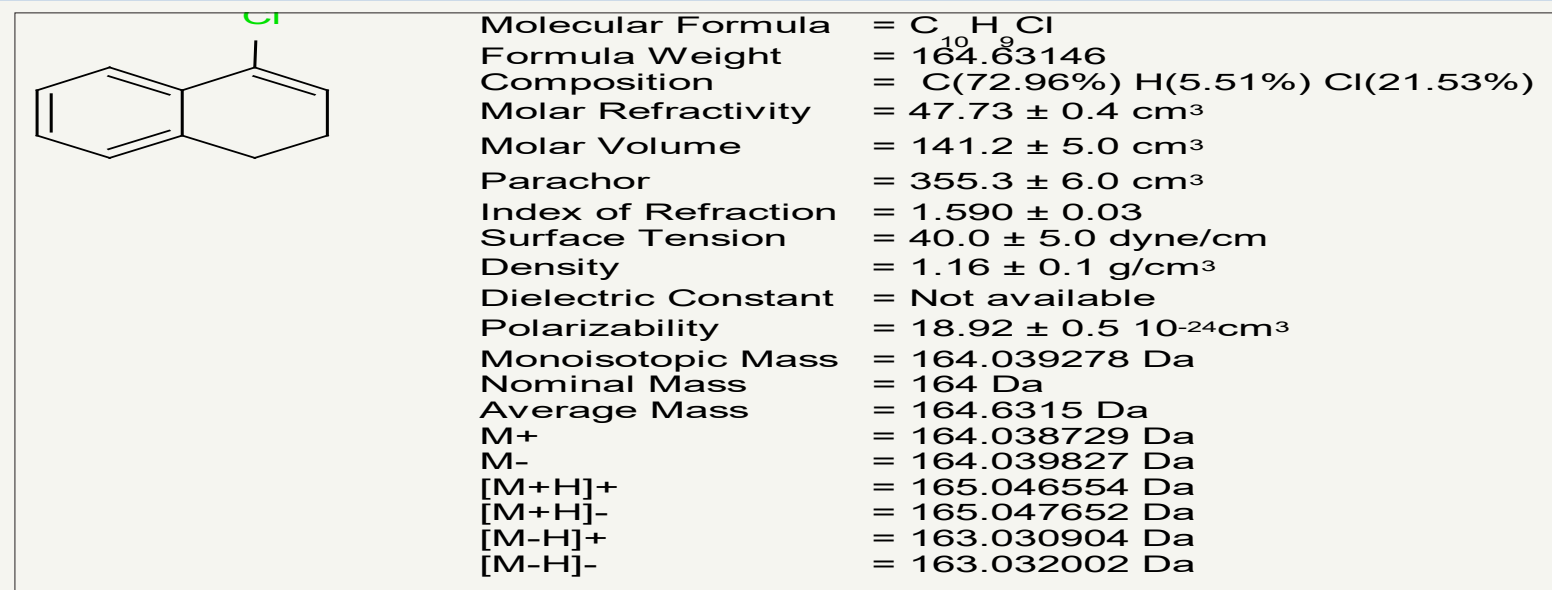

Figure 2: $\mathrm{H}^{1} \mathrm{NMR}$ of 4-chloro-1, 2-dihydronaphthalene.

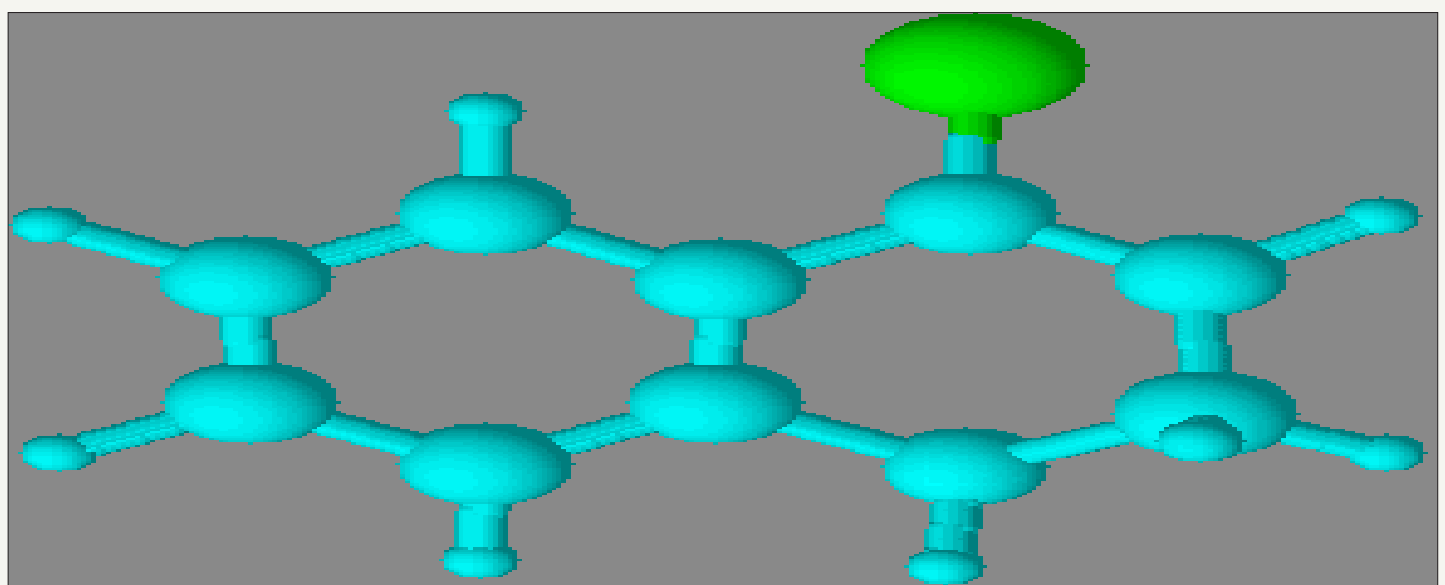

Figure 3: XRD of 4-chloro-1,2-dihydronaphthalene. 
Scheme2: synthesis of 1,2-didehydro-3,4-dihydronaphthalene

4-Chloro-1, 2-dihydronaphthalene (10gm) kept in two neck round bottle flask and potassium t-butaoxide (25gm) dissolved in THF solution. This solution poured into 4-Chloro-1, 2-dihydronaphthalene and reaction temperature $0{ }^{\circ} \mathrm{C}$. The reaction was mixture stirring four hours after completion reaction added cyclohexene as trapping agent and again stirring reaction more two hours. After work up got adduct $90 \%$ of 1, 2-didehydro-3, 4-dihydronaphthalene (Figure 4 \& 5).<smiles>CC1=CCCc2ccccc21</smiles>

4-chloro-1,2-dihydronaphthalene<smiles>C1#Cc2ccccc2CC1</smiles>

1,2-didehydro-3,4-dihydronaphthalene

Figure 4: Physical properties of 1, 2-didehydronaphthalene.<smiles>C1#Cc2ccccc2CC1</smiles>

Figure 5: $\mathrm{H}^{1} \mathrm{NMR}$ of 1, 2-didehydronaphthalene.

Molecular Formula
Formula Weight
Composition
Molar Refractivity
Molar Volume
Parachor
Index of Refraction
Surface Tension
Density
Dielectric Constant
Polarizability
Monoisotopic Mass
Nominal Mass
Average Mass
M+
M-
$[M+H]+$
$[M+H]-$
$[M-H]+$
[M-H]-

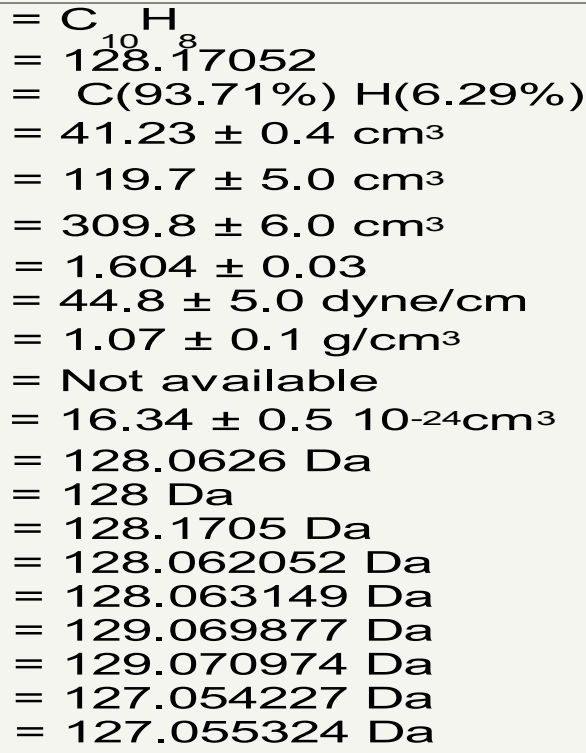

Scheme3: Synthesis of benzo-decahydrobiphenylene

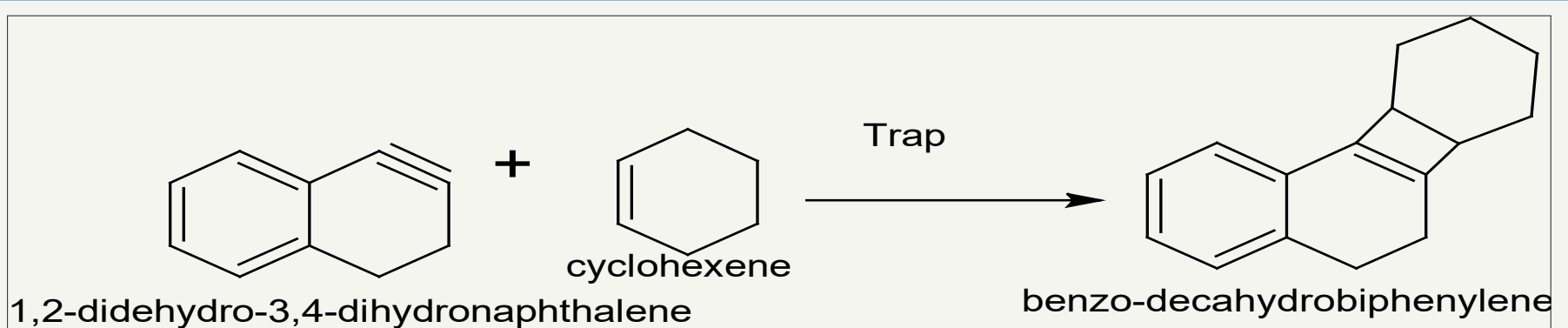

\section{1,2-didehydro-3,4-dihydronaphthalene}

benzo-decahydrobiphenylene

Figure 6: Physical properties of benzo-decahydrobiphenylene.

When 1, 2-didehydro-3, 4-dihydronaphthalene was dihydronaphthalene to yield benzo-decahydrobiphenylene (Figure used with cyclohexene, it was trapped by 1,2-didehydro-3,4- 6-8). 


$\begin{array}{ll}\text { Molecular Formula } & =\mathrm{C} \mathrm{H} \\ \text { Formula Weight } & =210.31412 \\ \text { Composition } & =\mathrm{C}(91.37 \%) \mathrm{H}(8.63 \%) \\ \text { Molar Refractivity } & =66.33 \pm 0.4 \mathrm{~cm}^{3} \\ \text { Molar Volume } & =191.6 \pm 5.0 \mathrm{~cm}^{3} \\ \text { Parachor } & =490.1 \pm 6.0 \mathrm{~cm}^{3} \\ \text { Index of Refraction } & =1.608 \pm 0.03 \\ \text { Surface Tension } & =42.7 \pm 5.0 \mathrm{dyn} / \mathrm{cm} \\ \text { Density } & =1.09 \pm 0.1 \mathrm{~g} / \mathrm{cm}^{3} \\ \text { Dielectric Constant } & =3.09 \pm 0.2 \\ \text { Polarizability } & =26.29 \pm 0.510-24 \mathrm{~cm}^{3} \\ \text { Monoisotopic Mass } & =210.140851 \mathrm{Da} \\ \text { Nominal Mass } & =210 \mathrm{Da} \\ \text { Average Mass } & =210.3141 \mathrm{Da} \\ \mathrm{M}+ & =210.140302 \mathrm{Da} \\ \mathrm{M}- & =210.141399 \mathrm{Da} \\ {[\mathrm{M}+\mathrm{H}]+} & =211.148127 \mathrm{Da} \\ {[\mathrm{M}+\mathrm{H}]-} & =211.149224 \mathrm{Da} \\ {[\mathrm{M}-\mathrm{H}]+} & =209.132477 \mathrm{Da} \\ {[\mathrm{M}-\mathrm{H}]-} & =209.133574 \mathrm{Da}\end{array}$

Figure 7: $\mathrm{H}^{1} \mathrm{NMR}$ of benzo-decahydrobiphenylene.

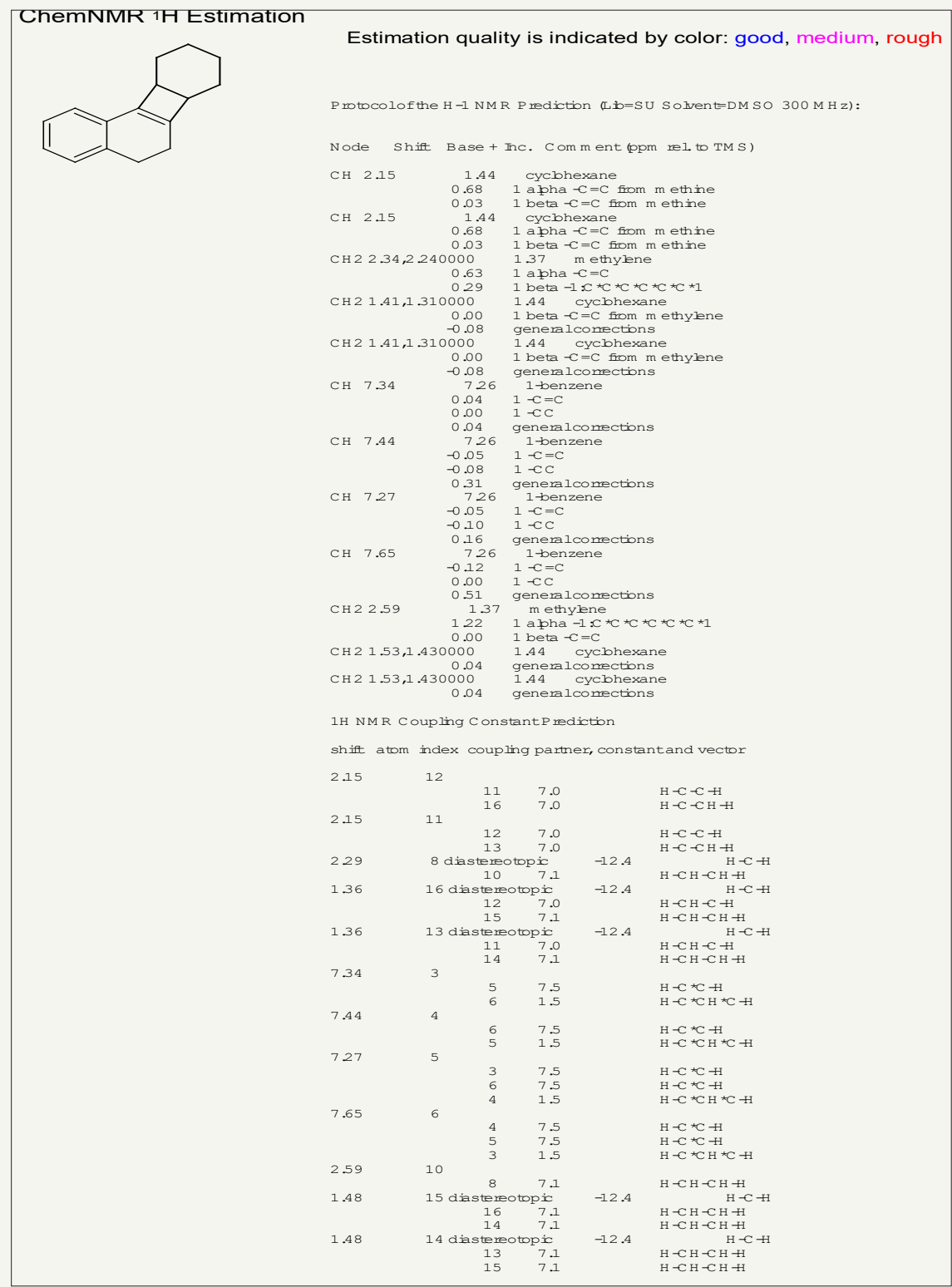

Figure 8: 
Scheme4: Synthesis of octahydrodibenzo [a,d] [8] annulene-5, 12-dione

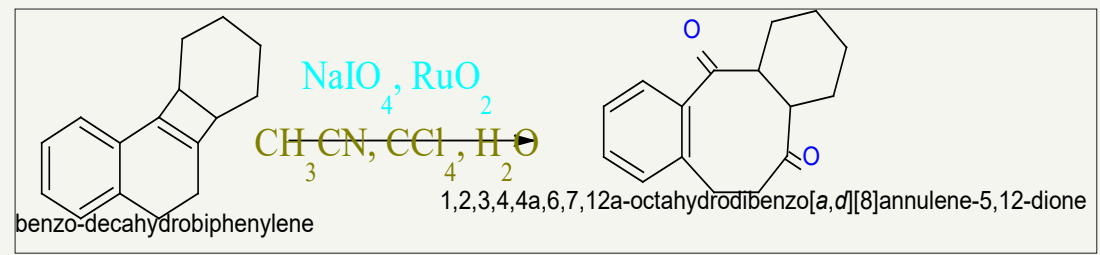

Figure 9: Physical properties of octahydrodibenzo[a,d][8]annulene-5,12-dione.

$\begin{array}{ll}\text { Molecular Formula } & =\mathrm{C} \mathrm{H} O \\ \text { Formula Weight } & =242.31292 \\ \text { Composition } & =\mathrm{C}(79.31 \%) \mathrm{H}(7.49 \%) \mathrm{O}(13.21 \%) \\ \text { Molar Refractivity } & =69.02 \pm 0.3 \mathrm{~cm}^{3} \\ \text { Molar Volume } & =216.7 \pm 3.0 \mathrm{~cm}^{3} \\ \text { Parachor } & =549.8 \pm 6.0 \mathrm{~cm}^{3} \\ \text { Index of Refraction } & =1.549 \pm 0.02 \\ \text { Surface Tension } & =41.4 \pm 3.0 \text { dyne/cm } \\ \text { Density } & =1.118 \pm 0.06 \mathrm{~g} / \mathrm{cm}^{3} \\ \text { Dielectric Constant } & =\text { Not available } \\ \text { Polarizability } & =27.36 \pm 0.510-24 \mathrm{~cm}^{3} \\ \text { Monoisotopic Mass } & =242.13068 \mathrm{Da} \\ \text { Nominal Mass } & =242 \mathrm{Da} \\ \text { Average Mass } & =242.3129 \mathrm{Da} \\ \mathrm{M}+ & =242.130131 \mathrm{Da} \\ \mathrm{M}- & =242.131228 \mathrm{Da} \\ {[\mathrm{M}+\mathrm{H}]+} & =243.137956 \mathrm{Da} \\ {[\mathrm{M}+\mathrm{H}]-} & =243.139053 \mathrm{Da} \\ {[\mathrm{M}-\mathrm{H}]+} & =241.122306 \mathrm{Da} \\ {[\mathrm{M}-\mathrm{H}]-} & =241.123403 \mathrm{Da}\end{array}$

Figure 10: $\mathrm{H}^{1} \mathrm{NMR}$ of octahydrodibenzo [a, d] [8] annulene-5, 12-dione.

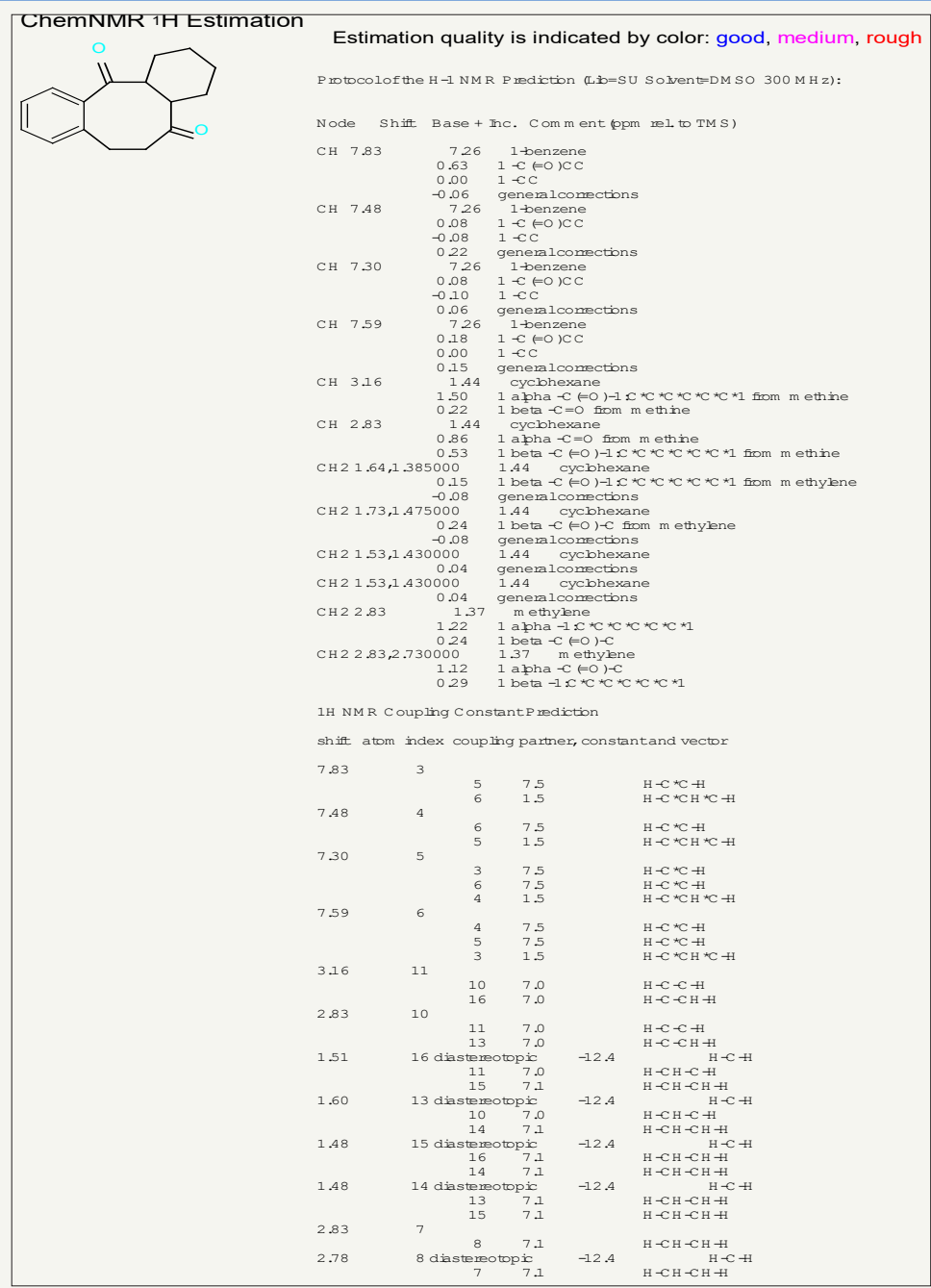

Figure 11: 
Adduct (20gm) oxidized into benzo-decahydrobiphenylene with addition of $\mathrm{NaIO}_{4}(10 \mathrm{gm})$ and $\mathrm{RuO}_{2}(15 \mathrm{~g})$ in the presence of solvent $\mathrm{CH}_{3} \mathrm{CN}$ and $\mathrm{CCl}_{4}$. The reaction was quenched with $\mathrm{H}_{2} \mathrm{O}$ and after workup 87\% yield of octahydrodibenzo [a,d] [8] annulene-5, 12-dione was obtained (Figure 9-11).

\section{Scheme5: Synthesis of octahydrodibenzo[a,d][8]annulene-5,12-dioxime}<smiles>O=C1CCc2ccccc2C(=O)C2CCCCC12</smiles>
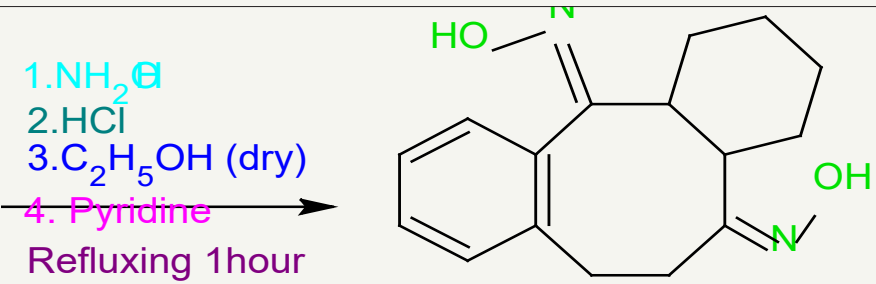

Octahydrodibenzo[a,d][8]annulene-5,12-dioxime

\section{Octahydrodibenzo[a,d][8]annulene-5,12-dione}

Figure 12: Physical properties of octahydrodibenzo [a,d] [8] annulene-5, 12-dioxime.

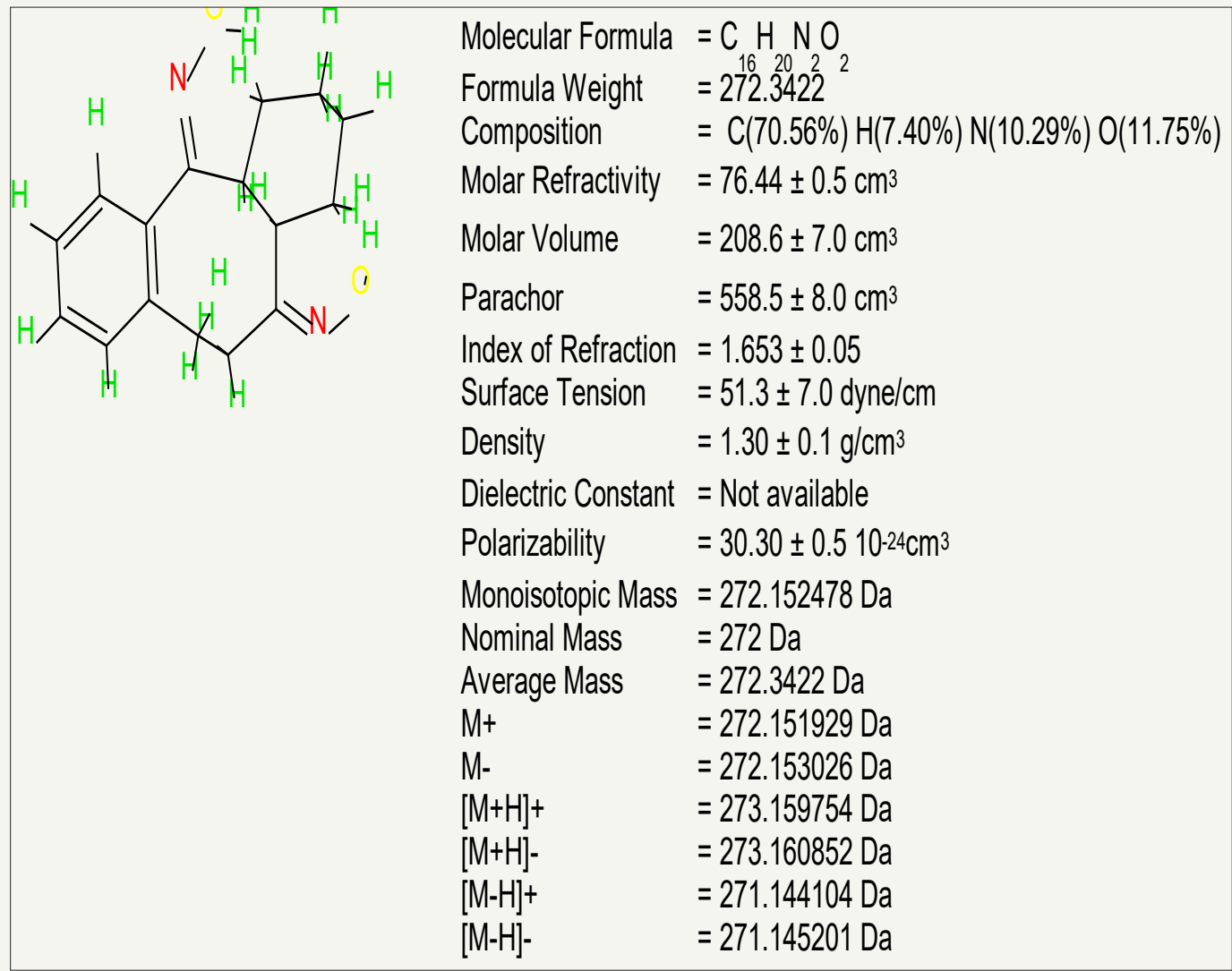

Figure 13: XRD of octahydrodibenzo [a,d] [8] annulene-5, 12-dihydrazone.

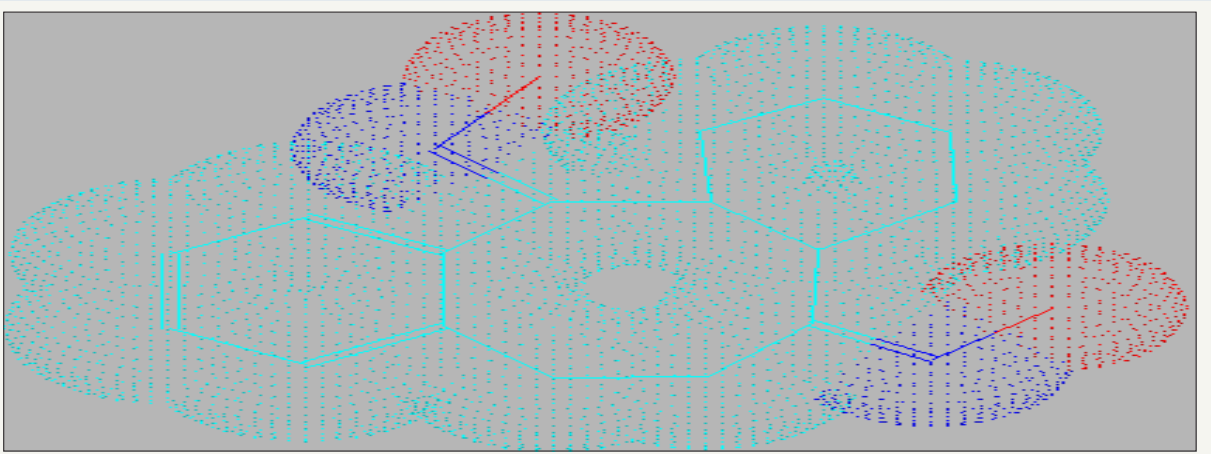

Figure 14: 
Octahydrodibenzo [a,d] [8] annulene-5,12-dione (30g), hydroxylamine hydrochloride $(50 \mathrm{~g})$ and $135 \mathrm{ml}$ of dry ethanol were taken and adding $70 \mathrm{ml}$ of pyridine and refluxing reaction mixture for two hours. Solvent was removed by use of rotator vapor and water was added in reaction mixture and after cooling the reaction by ice, solution was stirred until oxime crystallized. Solid was filtered and washed with a little water and then dried. The product was re-crystallized with ethanol and $71 \%$ yield of octahydrodibenzo $[a, d][8]$ annulene-5, 12-dioxime was obtained (Figure 12-14).

\section{Results and Discussion}

Marine water generates hostile environment for polybutadiene-coated mild steel. Corrosion is control in such hostile environment by the use of nanocoating and filler materials. Polybutadiene-coated mild steel corrosion rates were studied in marine water environment at $283,293,303,313$ and $323{ }^{\circ} \mathrm{K}$ temperatures after interval of 2, 5, 8, 11 and 14days with the help of gravimetric method equation $\mathrm{K}(\mathrm{mmpy})=13.56 \mathrm{X}$ (W/D At) (where W=weight loss of test coupon expressed in $\mathrm{kg}, \mathrm{A}=$ area of test coupon in square meter, $\mathrm{D}=$ Density of the material in $\mathrm{kg} \cdot \mathrm{m}^{-3}$ ) and their values recorded in Table 1. Similarly, the samples of poly-butadiene-coated mild steel nanocoated with octahydrodibenzo [a,d] [8] annulene-5, 12-dioxime and $\mathrm{ZnS}$ filler were immersed into marine water and corrosion rate was calculated on above mentioned temperatures and days and their values were mentioned in Table 1. Figure 15 plotted between corrosion rate $\mathrm{K}(\mathrm{mmpy})$ versus times $(\mathrm{t})$ in days which produced straight line and it indicated that corrosion rate of polybutadiene-coated mild steel increased without coating and their values were reduced after nanocoating and filler compounds. The results of Table 1 were shown that the corrosion rate of material is reduced by the action of nanocoating and filler compounds.

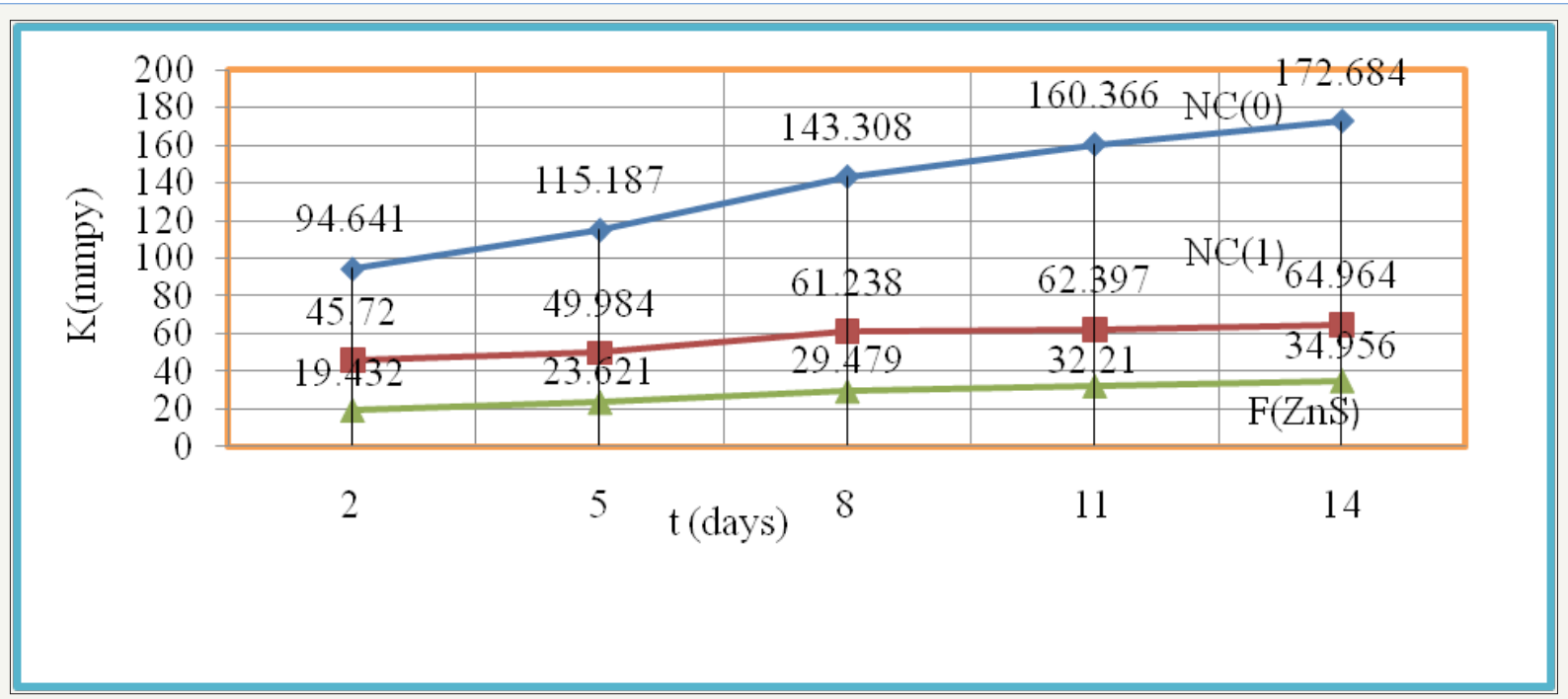

Figure 15: K (mmpy) Vs t (days) for nanocoating of $\mathrm{NC}$ (1) \& $\mathrm{ZnS}$ filler on polybutadiene-coated mild steel.

Table 1: Corrosion rate of polybutadine-coated mild steel nanocoated with octahydrodibenzo [a,d] [8] annulene-5,12dioxime[NC(1)] and $\mathrm{ZnS}$ filler in marine water.

\begin{tabular}{|c|c|c|c|c|c|c|c|}
\hline \multirow{2}{*}{ N C \& F } & $\operatorname{Temp}\left({ }^{0} \mathrm{~K}\right)$ & 283 & 293 & 303 & 313 & 323 & $\mathrm{C}(\mathrm{mM})$ \\
\hline & Time(days) & 2 & 5 & 8 & 11 & 14 & \\
\hline \multirow{2}{*}{ NC(0) } & $\mathrm{K}$ & 94.641 & 115.187 & 143.308 & 160.366 & 172.684 & \multirow{2}{*}{0} \\
\hline & $\log K$ & 1.976 & 2.061 & 2.156 & 2.205 & 2.237 & \\
\hline \multirow{8}{*}{ NC(1) } & $\mathrm{K}$ & 45.72 & 49.984 & 61.238 & 62.397 & 64.964 & \multirow{8}{*}{50} \\
\hline & $\log K$ & 1.66 & 1.698 & 1.787 & 1.795 & 1.812 & \\
\hline & $\log (\mathrm{K} / \mathrm{T})$ & 1.109 & 1.166 & 1.268 & 1.291 & 1.322 & \\
\hline & $\theta$ & 0.5169 & 0.566 & 0.5721 & 0.6109 & 0.6237 & \\
\hline & $(1-\theta)$ & 0.4831 & 0.444 & 0.4279 & 0.3891 & 0.3263 & \\
\hline & $(\theta / 1-\theta)$ & 1.069 & 1.274 & 1.336 & 1.57 & 1.657 & \\
\hline & $\log (\theta / 1-\theta)$ & 0.028 & 0.105 & 0.125 & 0.195 & 0.219 & \\
\hline & $\% \mathrm{CE}$ & 51.69 & 56.6 & 57.21 & 61.09 & 62.37 & \\
\hline
\end{tabular}




\begin{tabular}{|c|c|c|c|c|c|c|c|}
\hline \multirow{5}{*}{} & $\mathrm{K}$ & 19.432 & 23.621 & 29.479 & 32.21 & 34.956 \\
\cline { 2 - 7 } & $\log \mathrm{K}$ & 1.288 & 1.373 & 1.469 & 1.507 & 1.543 \\
\cline { 2 - 7 } & $\log (\mathrm{K} / \mathrm{T})$ & 0.74 & 0.84 & 0.95 & 1.004 & 1.053 \\
\cline { 2 - 7 } & $\theta$ & 0.7946 & 0.7949 & 0.7942 & 0.7987 & 0.7967 \\
\cline { 2 - 8 } & $(1-\theta)$ & 0.2054 & 0.2051 & 0.2058 & 0.2013 & 0.2039 \\
\cline { 2 - 8 } & $(\theta / 1-\theta)$ & 3.868 & 3.875 & 3.859 & 3.967 & 0.918 \\
\cline { 2 - 8 } & $\log (\theta / 1-\theta)$ & 0.587 & 0.588 & 0.586 & 0.598 & 79.87 & 79.67 \\
\hline
\end{tabular}

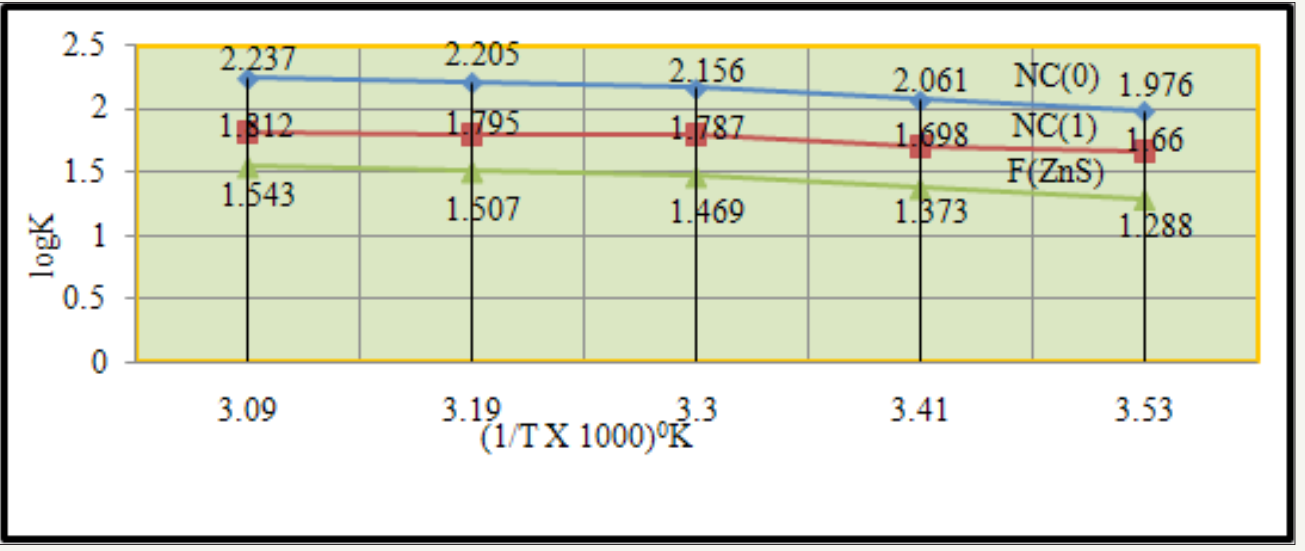

Figure 16: $\log \mathrm{K}$ Vs $1 / \mathrm{T}$ for nanocoating NC (1) \& ZnS filler on poly-butadiene-coated mild steel.

The octahydrodibenzo [a,d] [8] annulene-5, 12-dioxime is an electronic rich compound and large molecular weight so it is suitable for nanocoating materials. Nanocoating compound is coordinated its electron to ZnS filler thus they can form strong barrier on the surface of poly-butadiene-coated mild steel. This barrier stops osmosis or diffusion process of saline water. Studied the effect of temperature on the poly-butadiene-coated mild steel at mentioned above temperatures and their results were written in Table 1, it observed that corrosion rate of material increased without nanocoating but its values were reduced with nanocoating and filler compounds such types trends clearly noticed in Figure 16 which plotted between $\operatorname{logK}$ versus $1 / \mathrm{T}$ found to be a straight line. Nanocoating and filler compounds were formed a stable barrier with on the surface of poly-butadiene-coated mild steel. This barrier has thermal stability and suppressed the attack of $\mathrm{Cl}^{-}$ions. Nanocoating and filler materials were developed composite barrier i.e. stable in saline water as temperature increased.

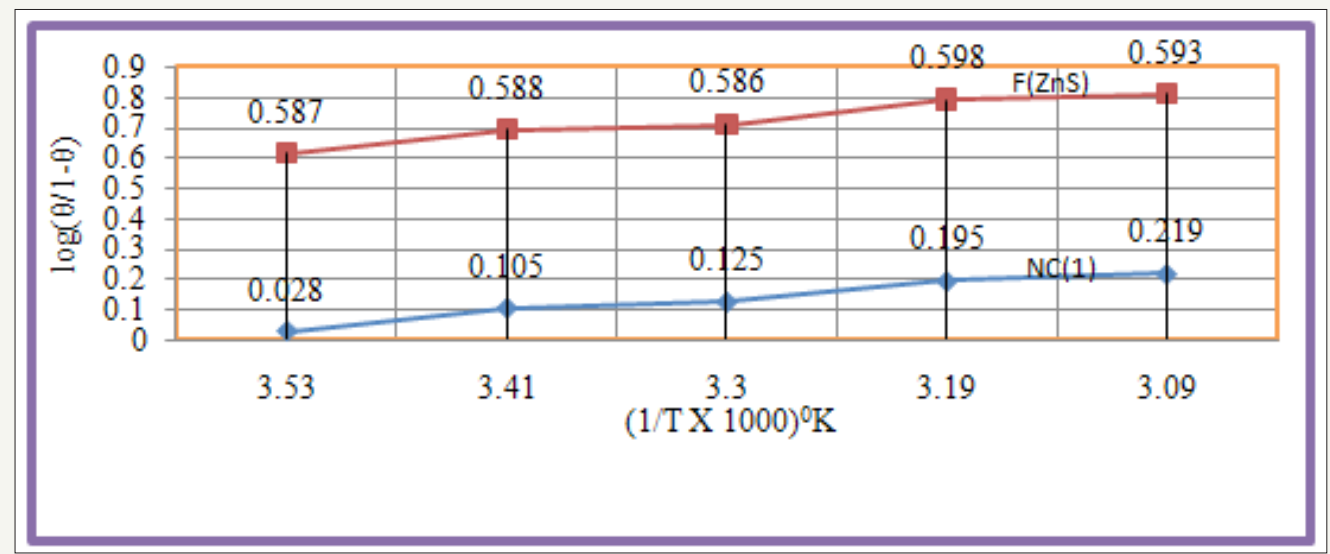

Figure 17: $\log (\theta / 1-\theta)$ Vs $1 /$ T for nanocoating of NC (1) \& ZnS filler on polybutadiene-coated mild steel.

The plot of $\log (\theta / 1-\theta)$ versus $1 / \mathrm{T}$ depicted a linear graph as shown in Figure 17. The plot of Figure 17 and Table 1 results confirmed that nanocoating compound octahydrodibenzo [a,d] [8] annluene-5, 12-dioxime and $\mathrm{ZnS}$ filler increased $\log (\theta / 1-\theta)$ as temperature enhanced. The values of $\log (\theta / 1-\theta)$ increased with octahydrodibenzo [a,d] [8] annluene-5, 12-dioxime but its values more increased with $\mathrm{ZnS}$ filler in marine water system. The surface coverage area $(\theta)$ of nanocoating compound octahydrodibenzo [a,d] [8] annluene-5, 12-dioxime and $\mathrm{ZnS}$ filler was calculated by equation $\theta=\left(1-K / K_{0}\right.$ ) (where $K$ is the corrosion rate before coating and $\mathrm{K}_{\mathrm{o}}$ is the corrosion rate after coating) and their values were mentioned in Table 1. Figure 18 plotted between surface coverage 
$(\theta)$ versus temperature $(\mathrm{T})$ which indicated that filler compound covered more surface area with respect of nanocoating compound octahydrodibenzo [a,d] [8] annluene-5, 12-dioxime. The low dose of nanocoating and filler compounds were occupied more surface coverage area as temperatures were increased. These results were given information that as temperatures were risen nanocoating and filler compounds were accommodated more surface areas.

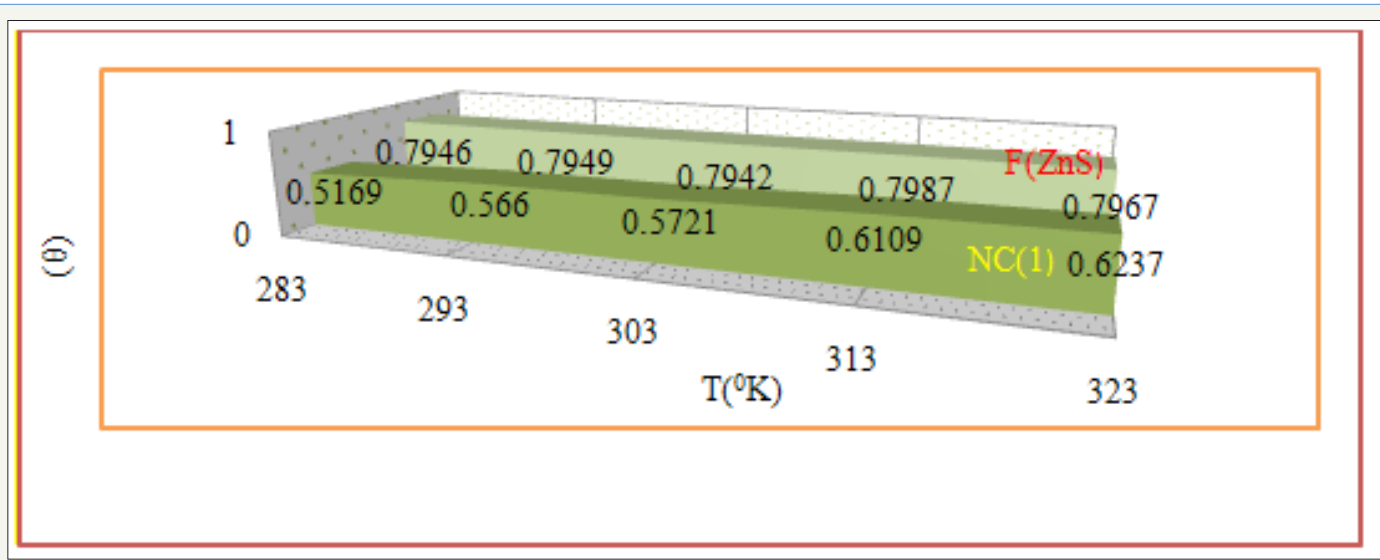

Figure 18: $\theta$ Vs T for nanocoating of NC (1) \& ZnS filler on the poly-butadiene-coated mild steel.

The percentage coating efficiency for octahydrobenzo [a,d] [8] annulene-5, 12-dioxime and $\mathrm{ZnS}$ filler were calculated by equation, $\% \mathrm{CE}=\left(1-\mathrm{K} / \mathrm{K}_{\mathrm{o}}\right) \mathrm{X} 100$ (where $\mathrm{CE}=$ coating efficiency, $\mathrm{K}=$ Corrosion rate after coating, $\mathrm{K}_{\mathrm{o}}=$ corrosion rate before coating) and their values were given in Table 1. Figure 19 plotted between percent CE (percentage coating efficiency) versus $\mathrm{T}$ (temperature) indicated that filler compound enhanced percentage coating efficiency with respect of nanocoating compound. Nanocating and filler compounds were electron rich compound so they have more binding capacities. Activation energy of polybutadiene-coated mild steel, nanocoating compound octahydrodibenzo [a,d] [8] annulene-5, 12-dioxime and
ZnS filler were determined by Arrhenius equation, $d / d t(\log K)=E_{a} /$ $\mathrm{RT}^{2}$ (where $\mathrm{T}$ is temperature in Kelvin, $\mathrm{R}$ is universal gas constant and $E_{a}$ is the activation energy of the reaction) and Figure 16 which plotted between $\log$ K versus 1/T. The calculated values of activation energies were mentioned in Table 2. Poly-butadiene-coated mild steel produced high activation energies at different temperatures in marine water whereas nanocoating and filler compounds exhibited lower activation energy. The results of activation energies were shown that nanocoating and filler compounds adhered on the surface of poly-butadiene-coated mild steel by chemical bonding.

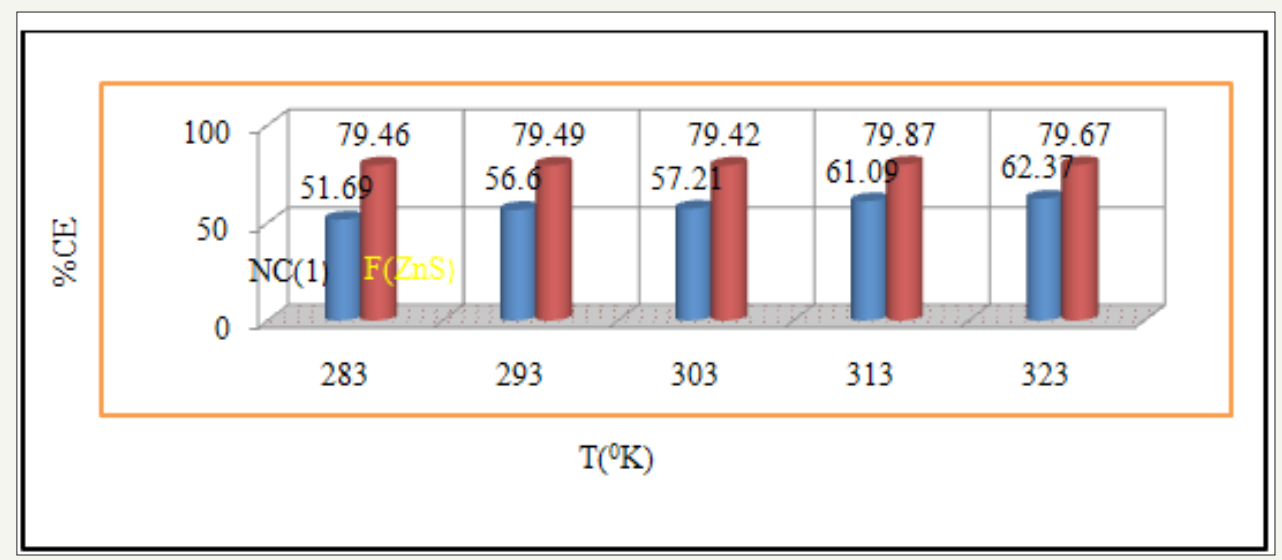

Figure 19: $\theta$ Vs T for nanocoating of NC (1) \& ZnS filler on poly-butadiene-coated mild steel.

Table 2: Thermal parameters of nanocoating compound octahydrodibenzo [a,d] [8] annulene-5, 12-dioxime and $\mathrm{ZnS}$ filler coated on poly-butadiene-coated mild steel in marine water

\begin{tabular}{|c|c|c|c|c|c|}
\hline Thermal Parameters & $283^{\circ} \mathrm{K}$ & $293{ }^{\circ} \mathrm{K}$ & $303{ }^{\circ} \mathrm{K}$ & $313{ }^{\circ} \mathrm{K}$ & 139.19 \\
\hline $\mathbf{E}_{\mathrm{a}}(\mathbf{0})$ & 133.43 & 134.44 & 136.1 & 109.53 & 107.11 \\
\hline $\mathbf{E}_{\mathrm{a}}, \mathbf{N C}(\mathbf{1})$ & 113.15 & 110.76 & 112.81 & -11.89 & -12.94 \\
\hline $\mathbf{q}, \mathbf{N C}(\mathbf{1})$ & -1.89 & -6.84 & -7.89 & -202.45 & -197.94 \\
\hline$\Delta \mathbf{G}, \mathbf{N C}(\mathbf{1})$ & -214.91 & -210.13 & -208.92 & 23 \\
\hline
\end{tabular}




\begin{tabular}{|c|c|c|c|c|c|}
\hline$\Delta \mathrm{H}, \mathrm{NC}(1)$ & -75.11 & -76.06 & -80.07 & -78.8 & -78.11 \\
\hline$\Delta S, \operatorname{NC}(1)$ & -82.15 & -83.92 & -87.57 & -88.16 & -89.07 \\
\hline$\theta, \mathrm{NC}(1)$ & 0.5169 & 0.566 & 0.5721 & 0.6109 & 0.6237 \\
\hline$E_{a^{\prime}}, \mathrm{NC}(\mathrm{ZnS})$ & 86.97 & 89.56 & 92.73 & 91.96 & 91.2 \\
\hline$q, \mathrm{NC}(\mathrm{ZnS})$ & -39.63 & -38.35 & -36.99 & -36.49 & -35.05 \\
\hline$\Delta \mathrm{G}, \mathrm{NC}(\mathrm{ZnS})$ & -189.82 & -188.89 & -188.87 & -184.93 & -181.23 \\
\hline$\Delta \mathbf{H}$ & -50.02 & -54.83 & -60.03 & -61.28 & -62.27 \\
\hline NC(ZnS) & -67.94 & -71.47 & -75.42 & -61.28 & -78.8 \\
\hline$\Delta S, N C(F)$ & -67.94 & -71.47 & -75.42 & -77.08 & -78.8 \\
\hline$\theta, \mathrm{NC}(\mathbf{Z n S})$ & 0.7946 & 0.7949 & 0.7942 & 0.7987 & 0.7967 \\
\hline
\end{tabular}

Table 2 Thermal parameters of nanocoating compound octahydrodibenzo [a,d] [8] annulene-5, 12-dioxime and ZnS filler coated on poly-butadiene-coated mild steel in marine water. Heat of adsorption of nanocoating compound octahydrodibenzo [a,d] [8] annulene-5, 12-dioxime and $\mathrm{ZnS}$ filler were calculated by Langmuir equation, $\log (\theta / 1-\theta)=\log (A . C)-\left(\mathrm{q}_{\mathrm{ads}} / 2.303 \mathrm{R}\right.$ T) (where $\mathrm{T}$ is temperature in Kelvin and $\mathrm{q}_{\mathrm{ads}}$ heat of adsorption) and Figure 17 plotted against $\log (\theta / 1-\theta)$ versus $1 / \mathrm{T}$ which produced straight lines. Heat adsorption values found to be negative with nanocoating and filler compounds so the formation of composite barrier is a chemical process. These compounds were adhered with base material by chemical bonding. Free energies of both compounds give information that coating is an exothermic process. It is clear by data calculated for octahydrodibenzo [a,d] [8] annulene-5, 12-dioxime and $\mathrm{ZnS}$ filler with the help of equation, $\Delta \mathrm{G}=-2.303 \mathrm{RT}$ $\log (33.3 \mathrm{~K})$ (where $\mathrm{R}$ is universal gas constant, $\mathrm{T}$ be temperature and $\mathrm{K}$ corrosion rate) and their values were written in Table 2. Both compounds were produced a negative heat of adsorption which indicated that they formed chemical bonding during nanocoating process.

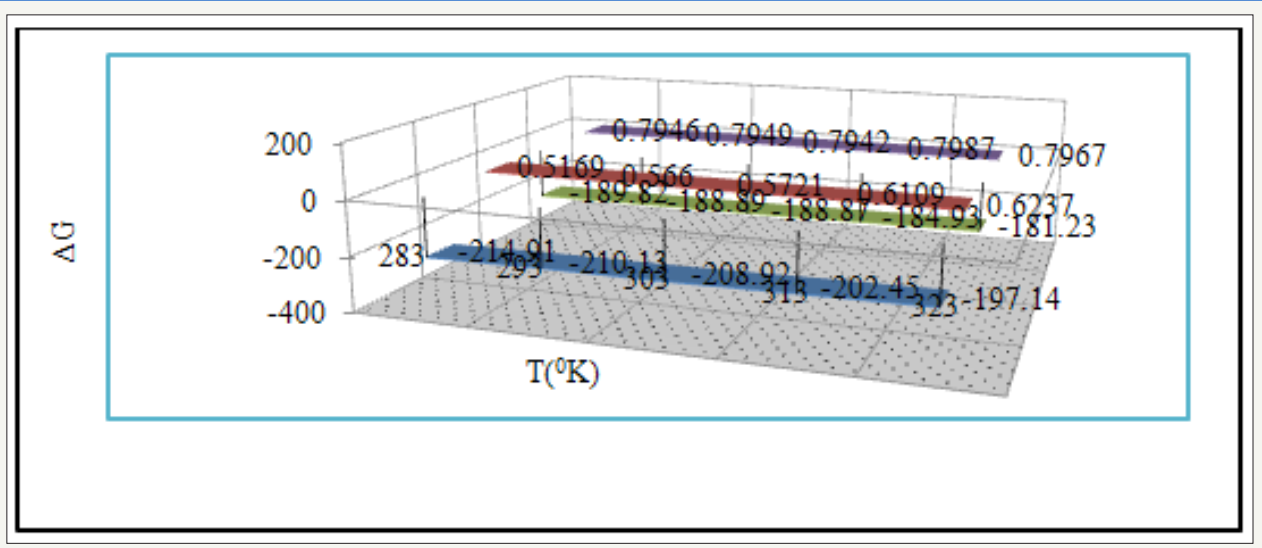

Figure 20: $\Delta \mathrm{G}$ Vs $\mathrm{T}$ for $(\theta)$ for nanocoating of NC (5) \& $\mathrm{ZnS}$ filler on poly-butadiene-coating mild steel.

Enthalpy and entropy are very important thermal parameters which give information about nanocoating and filler compounds bonding nature with base materials. The values of enthalpy and entropy for octahydrodibenzo [a,d] [8] annulene-5, 12-dioxime and $\mathrm{ZnS}$ filler were calculated by transition state equation, $\mathrm{K}=\mathrm{RT} / \mathrm{N} \mathrm{h}$ $\log \left(\Delta S^{\#} / R\right) X \log \left(-\Delta H^{\#} / R T\right)$ (where $N$ is Avogadro's constant, $h$ is Planck's constant, $\Delta \mathrm{S}^{\#}$ is the change of entropy activation and $\Delta \mathrm{H}^{\#}$ is the change of enthalpy activation) and Figure 20 and their values were recorded in Table 2. The results of enthalpy and entropy were shown that both compounds were adsorbed with the base materials by chemical bonding. Such coating is an exothermic process. The negative entropy indicated that nanocoating and filler compounds accommodated on the surface of poly-butadiene-coated mild steel in an ordered matrix. Figure 20 plotted between free energy $(\Delta \mathrm{G})$ and temperatures for surface coverage area $(\theta)$ occupied by octahydrodibenzo [a,d] [8] annulene-5, 12-dioxime and ZnS filler that confined free energy decreased when temperatures increased but at this moment surface coverage area was enhanced.

Table 3: Potentiostat polarization of octahydrodibenzo [a,d] [8] annulene-5, 12-dioxime and ZnS nanocoated on polybutadiene-coated mild steel in marine water.

\begin{tabular}{|c|c|c|c|c|c|c|c|c|c|}
\hline $\mathbf{N C}$ & $\Delta \mathbf{E}(\mathbf{m V})$ & $\Delta \mathbf{I}$ & $\beta_{\mathrm{a}}$ & $\beta_{\mathbf{c}}$ & $\mathbf{I c o r r}\left(\mathbf{m A} / \mathbf{c m}^{\mathbf{2}}\right)$ & $\mathbf{K}(\mathbf{m m p y})$ & $\theta$ & $\mathbf{\%} \mathbf{C E}$ & $\mathbf{C}(\mathbf{m M})$ \\
\hline $\mathrm{NC}(0)$ & -451 & 112 & 172 & 151 & 8.69 & 264.69 & 0 & 0 & 0 \\
\hline $\mathrm{NC}(1)$ & -412 & 99 & 112 & 165 & 7.02 & 213.82 & 0.71 & 71 & 50 \\
\hline $\mathrm{F}(\mathrm{ZnS})$ & -350 & 85 & 101 & 175 & 6.77 & 206.21 & 0.88 & 88 & 10 \\
\hline
\end{tabular}




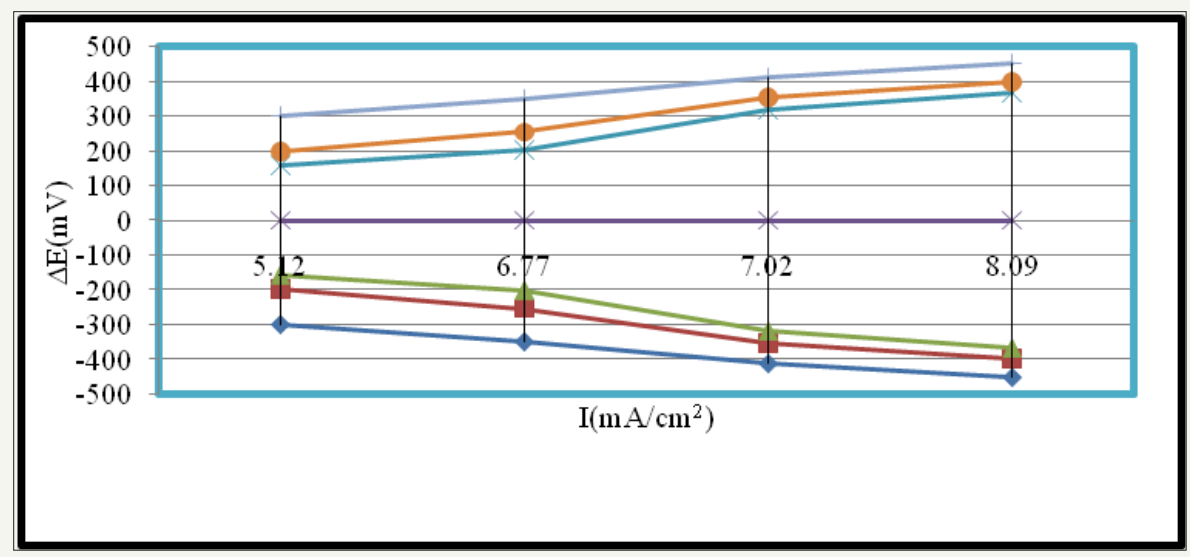

Figure 21: $\Delta \mathrm{E}(\mathrm{mV}) \mathrm{Vs} I(\mathrm{~mA} / \mathrm{cm} 2)$ for nanocoating of $\mathrm{NC}(1) \&$ filler $\mathrm{ZnS}$ on poly-butadiene-coated mild steel.

The corrosion potential, corrosion current and corrosion current density of poly-butadiene-coated mild steel, nanocoated octahydrodibenzo [a,d] [8] annulene and $\mathrm{ZnS}$ filler were calculated by equation, $\Delta \mathrm{E} / \Delta \mathrm{I}=\beta_{\mathrm{a}} \beta_{\mathrm{c}} / 2.303 \mathrm{I}_{\text {corr }}\left(\beta_{\mathrm{a}}+\beta_{\mathrm{c}}\right)$ (where $\Delta \mathrm{E} / \Delta \mathrm{I}$ is the slope which linear polarization resistance $\left(\mathrm{R}_{\mathrm{p}}\right), \beta_{\mathrm{a}}$ and $\beta_{\mathrm{c}}$ are anodic and cathodic Tafel slope respectively and $I_{\text {corr }}$ is the corrosion current density in $\mathrm{mA} / \mathrm{cm}^{2}$ ) and Tafel plot between electrode potential $(\Delta \mathrm{E})$ versus current density (I) and their values were mentioned. It was observed that electrode potential and corrosion current density were high with polybutadiene whereas anodic current density increased and cathodic density current reduced. But octahydrodibenzo [a,d] [8] annulene-5, 12-dioxime and $\mathrm{ZnS}$ filler reduced electrode potential and corrosion current density. Tafel plot of Figure 21 and the results of Table 3 indicated that nanocoating and filler compounds minimized anodic current and maximized cathodic current. These results confirmed that nanocoaing and filler compounds developed a strong barrier on the poly-butadiene-coated mild steel which neutralized the attack of saline water and carbonic acid.

The corrosion current was obtained by above equation and Tafel graph of Figure 21 for poly-butadiene-coated mild steel, nanocoated octahydrodibenzo [a,d] [8] annulene and $\mathrm{ZnS}$ filler and these values were put in equation, $\mathrm{C}$. $\mathrm{R}$ (mmpy) $=0.1288 \mathrm{I}(\mathrm{mA} /$ $\left.\mathrm{cm}^{2}\right) \times \mathrm{Eq} \cdot \mathrm{Wt}(\mathrm{g}) / \rho\left(\mathrm{g} / \mathrm{cm}^{3}\right)$ (where Iis the corrosion current density $\rho$ is specimen density and Eq. Wt is specimen equivalent weight) and their values were recorded in Table 3 . It was noticed that corrosion rate increased with poly-butadiene-coated mild steel and these values were reduced with nanocoating and filler compounds. The results of corrosion rate measured by weight loss experiment which confirmed the results of potentiostat.

\section{Conclusion}

It is very difficult to control corrosion of marine water. Polybutadiene-coated mild steel uses in marine water for different works but this material is face corrosion problem. In this research, it is tried to check corrosion of poly-butadiene mild steel by the application of nanocoating compound octahydrodibenzo [a,d] [8] annulene-5, 12-dioxime and filler $\mathrm{ZnS}$. The corrosion activities of poly-butadiene was studied at $283{ }^{\circ} \mathrm{K}, 293{ }^{\circ} \mathrm{K}, 303{ }^{\circ} \mathrm{K}, 313{ }^{\circ} \mathrm{K}$ and $323{ }^{\circ} \mathrm{K}$ temperatures and the concentration of nanocoating and filler compounds were taken in $50 \mathrm{mM}$ and $10 \mathrm{mM}$. The results of surface coverage areas and coating efficiencies of nanocoating and filler compounds were indicated these compounds had more coverage capability. Nanocoating and filler compounds results of activation energy, heat of adsorption, free energy, enthalpy and entropy were shown that these compounds were attached with base material by chemical bonding. They can form composite thin film barrier which is passive in corrosive environment. Filler material blocks the porosities of nanocoating compounds and stop osmosis or diffusion process of corrosive agents.

\section{Acknowledgement}

Author is very thankful to finical agency UGC-New Delhi, India providing research grant. I also give thanks my research Mr. Manjay Kumar Thakur for his laboratory work and data calculation.

\section{References}

1. Bhadra S, Singh NK, Khastgir D (2011), Polyaniline based anticorrosive and anti-molding coating. Journal of Chemical Engineering and Materials Science 2(1): 1-11.

2. Szabo T, Molnar-Nagy L, Telegdi J (2011) Self-healing microcapsules and slow release microspheres in paints. Progress in Organic Coatings 72(12): $52-57$.

3. Videla H, Herrera LK (2009) Understanding microbial inhibition of corrosion. Electrochem Acta 39: 229-234.

4. Wen NT, Lin CS, Bai CY, Ger MD (2008) Structures and characteristics of $\mathrm{Cr}$ (III) based conversion coatings on electrogalvanized steels. Surf Coat Technol 203(3-4): 317-323.

5. Boerio FJ, Shah P (2005) Adhesion of injection molded PVC to steel substrates. The Journal of Adhesion 81(6): 645-675.

6. Deveci H, Ahmetti G, Ersoz M (2012) Modified styrenes: Corrosion physico-mechanical and thermal properties evaluation. Prog Org Coat 73(1): 1-7.

7. Genzer J (2005) Templating Surfaces with Gradient Assemblies. Journal of Adhesion 81(3-4): 417-435.

8. Leon Silva U, Nicho ME (2010) Poly(3-octylthiophhene) and polystyrene blends thermally treated as coating for corrosion protection of stainless steel 304. J Solid State Electrochem 14(8): 1487-1497.

9. Baier RE (2006) Surface behaviour of biomaterials: Surface for biocompatibility. J Mater Sci Mater Med 17(11): 1057-1062. 
10. Rao BVA, Iqbal MY, Sreehar B (2010) Electrochemical and surface analytical studies of the self assembled monolayer of 5-methoxy2-(octadeclthiol) benzimidazole in corrosion protection of copper Electrochim Acta 55(3): 620-631.

11. Liu XY, Ma HY, Hou MZ (2009) Self-assembled monolayers of stearic imidazoline on copper electrodes detected using electro chemical measurement, XPS, molecular simulation and FTIR. Chinese Sci Bull 54(3): 374-381.

12. Liao QQ, Yue ZW, Zhou Q (2009) Corrosion inhibition effect of selfassembled monolayers of ammonium pyrrolidine dithiocarbamate on copper. Acta Phys Chin Sin 25(8): 1655-1661.

13. Zhang DQ He XM, Kim GS (2009) Arginine self-assembled monolayers against copper corrosion and synergetic effect of iodide ion. J Appl Electrochem 39(8): 1193-1198.

14. Ghareba GS, Omanovic S (2010) Interaction of 12-aminododecanoic acid with a carbon steel surface: Towards the development of 'green' corrosion inhibitors. Corrosion Sci 52(6): 2104-2113.

15. Sahoo RR, Biswas SK (2009) Frictional response of fatty acids on steel. ] Colloid Interf Sci 333(2): 707-718.

16. Raman R, Gawalt ES (2007) Self assembled mono layers of alkanoic acid on the native oxide surface of SS316L by solution deposition. Langmuir 23(5): 2284-2288.
17. Li DG, Chen SH, Zhao SY (2006) The corrosion Inhibition of the selfassembled $\mathrm{Au}$ and $\mathrm{Ag}$ nanoparticles films on the surface of copper. Colloid Surface A 273(1-3): 16-23.

18. Cristiani P, Perboni G, Debenedetti A (2008) Effect of chlorination on the corrosion of $\mathrm{Cu} / \mathrm{Ni} 70 / 30$ condenser tubing. Electrochim Acta 54(1): 100-107.

19. Cristiani P (2005) Solutions fouling in power station condensers. Appl Therm Eng 25(16): 2630-2640.

20. Bibber JW (2009) Chromium frees conversion coating for zinc and its alloys. Journal of Applied Surface Finishing 2(4): 273-275.

21. Singh RK (2016) Corrosion protection of transport vehicles by nanocoating of decahydrobenzo [8] annulene-5, 10-dihydrazone and SiC filler in $\mathrm{H}_{2} \mathrm{O}$ (moist), $\mathrm{CO}_{2}, \mathrm{SO}_{2}$ environments and weather change. Journal of Metallurgy and Materials Science 58: 167-179.

22. Singh RK (2017) Corrosion protection of transport vehicles by nanocoating of decahydrobenzo[8]annulene-5,10-dihydrazone in corrosive environments and weather change. Journal of Powder Metallurgy \& Mining 6(1): 2-8.

23. Singh RK (2017) Atmospheric corrosion protection of epoxy-coated stainless steel by nanocoating of decahydrobenzo [8] annulene-5, 10-disemecarbazone and TiN filler. International J of NME 2(4): 17-32.
Creative Commons Attribution 4.0 International License

For possible submissions Click Here

\section{Submit Article}

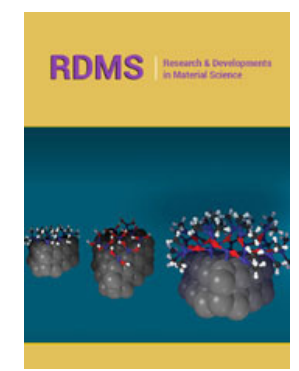

\section{Research \& Development in Material Science}

\section{Benefits of Publishing with us}

- High-level peer review and editorial services

- Freely accessible online immediately upon publication

- Authors retain the copyright to their work

- Licensing it under a Creative Commons license

- Visibility through different online platforms 